\title{
A New Measurement of Systemic Risk in China's Banking System
}

\author{
Yong $\mathrm{Li}^{1}$, Hulin $\mathrm{Zhao}^{2}$ \\ ${ }^{1}$ Business School, China University of Political Science and Law, Beijing, China \\ ${ }^{2}$ Business School, Gansu University of Political Science and Law, Lanzhou, China
}

Email address:

yyililei@163.com (Yong Li), 344406930@qq.com (Hulin Zhao)

\section{To cite this article:}

Yong Li, Hulin Zhao. A New Measurement of Systemic Risk in China's Banking System. Journal of Finance and Accounting. Vol. 9, No. 3, 2021, pp. 87-92. doi: 10.11648/j.jfa.20210903.14

Received: April 20, 2021; Accepted: June 4, 2021; Published: June 10, 2021

\begin{abstract}
At present, the measurement of systemic risk is still a worldwide challenge. The complex network theory provides a new perspective for the study of this problem. Based on the correlation coefficient between the banks calculated using their default probabilities, this paper builds China's banking networks for the periods of 2008-2019, and analyzes systematically the topological structure of the networks, and determine the size of the systemic risk from the perspective of network topology by using the corresponding characteristics of complex network with the feature of systemic financial risk. It is found that the systemic risk of China's banking industry has a declined tendency before 2018, and the main cause is due to the eigenvector centrality and clustering coefficient declined rapidly. However, after 2018, systemic risk showed a litter upward trend, and the increase of clustering coefficient and eigenvector centrality was the main reason for that upward trend. Before 2018, risk transmission was mainly taken place from local banks and joint-equity commercial banks to state-owned banks, which were the main risk bearers. After 2018, risk contagion mainly occurred among local banks, and some local banks role as systemically important ones. Therefore, dissolving the systemic financial risk in China should strengthen the regulation of local banks. In particular, the high-risk leverage operations and excessively innovative business should be strictly supervised so as to prevent the expansion and spread of the negative effects stemmed from maturity mismatch, maturity transformation and credit transformation.
\end{abstract}

Keywords: Banking Network, Probability of Default, Contagion Risk, Systemic Risk

\section{Introduction}

At present, how to measure systemic financial risk is still a worldwide challenge. The banking system plays a leading role in China's financial system. With the extension of the credit chain, the relationship between banks is becoming more and more complex, and its relationship network has gradually evolved into a highly intensive complex network. The bankruptcy and reorganization of Baoshang bank in May 2020 means that the government's credit guarantee will gradually withdraw from the banking system, the risk of individual banks is more easily spread in the banking network, Premier Li Keqiang clearly pointed out in the government work report of the "China two sessions" in March 2021 that it is necessary to "improve the working mechanism of financial risk disposal, compact the responsibilities of all parties, and firmly hold the bottom line of no systemic risk". Therefore, it is of great significance to strengthen the research on systemic risk measurement of banking system.

Due to complex networks and financial system has homogeneity in the formality, many complex network characteristics and systemic financial risk characteristics can be correspondingly to each other, and also due to complex networks can more accurately and vividly describe the complex relationship among the system subjects, more and more scholars use it to study the systemic risk of financial system [1-7]. The network construction is focused on how to determine the interconnection between nodes. At present, the main way to get the interconnection lines between nodes is by calculating the risk contagiousness among financial institutions. Taking into account the effect of investor panic and herd behavior, the characteristic index of the complex network is obtained by calculating the depth of risk 
contagion and the vulnerability of nodes to be attacked. There are three ways to calculate the risk contagious coefficient according to the different assumptions on the source of initial shock: The first way assumes that the initial shock comes from a failure of the bank in the system, the size of the contagion risk between nodes is driven by insolvency risk [8]. Liu [9] calculated their contagion risk weight with PageRank algorithm based on the implied failure probability of 26 commercial banks in China, and constructed a simulated risk contagion network of Chinese commercial banks. His study concluded that there was very low probability of contagion risk caused by the bankruptcy of the large state-owned commercial banks in China, but small and medium-sized commercial banks are not only the main initiator, but also the main undertaker of contagion risk.

The second way assumes that the initial shock is induced by extreme events, quantify the risks of individual financial companies and the whole financial system respectively through the extreme condition quantile of stock return distribution [10]. Suitable statistical inference reveals a multitude of relevant risk spillover channels and determines companies of systemic importance in the U.S. financial system. Zhang et al. [11] used the VAR model to construct a risk network of China's stock market, and studied the contribution of systemic risk of China's stock market from the perspective of the evolution of risk network. They believe that the occurrence of extreme volatility in the stock market was correlated with the accumulation of systemic risk. Network structure indexes such as node degree, proximity centrality and point intensity positively contribute significantly systemic risk. Li et al. [12] build a network of China's stock market crash in 2008 and 2015, their research suggests that China's stock market in crash statues have the features of small world and scale-free complex network, and select the systemically important stocks and systemically important industry based on their degree centrality, betweenness centrality and proximity centrality.

The third way assumes the initial shock is the probability of a bank defaulting, and measure systemic risk by the contagion of default probability. Giudici and Parisi [13] analyze the evolution of systemic risk using default probability for the 11 member states of the European Monetary Union (Germany, France, Belgium, Luxembourg, Austria, Finland, Ireland, Netherlands, Italy, and Spain). And Portugal), they conclude overall, the sovereign crisis has increased systemic risks more than the financial crisis. Tafakori et al. [14] studied the default dependence relationship among banks in the financial network, and analyzed the relevant structure and centrality of each bank by using the minimum spanning tree to identify the possible contagion mode and important banks that may pose a systemic threat. Liu and $\mathrm{Yu}$ [15] use the improved three-factor model to obtain the time-varying default probability of each bank through the stock price data of listed banks, and put it into the process of complex network analysis and simulation as the proxy variable of default risk. Their study reveals, from 2017 to 2019 , the vulnerability of $\mathrm{ICBC}, \mathrm{ABC}$ and $\mathrm{CCB}$ is relatively low, while the vulnerability of BCM and BOC is relatively high, so they should be regarded as systemically important banks. In addition, the local banks appear obviously risk aggregation effect.

It can be seen that the analysis of systemic risk using complex networks requires an assumption of a shock source. The first two assumptions about the shock source (i.e. the bank bankruptcy event as the shock and the tail risk induced by extreme events as the shock) do not conform to the actual situation in China. Although Chinese banks are allowed to go bankrupt, when there is a real bank crisis, in order to protect the safety of deposits and the rights and interests of customers, the central bank will inevitably rescue or take over them. Therefore, there is no real bank bankruptcy in China. The third assumption, based on the probability of default as a source of the shock, is more in line with China's case. Based on the balance sheet and stock price data of banks, this paper uses the KMV Model (Kealhofe-McQuown-Vasicek Model) proposed by KMV Company in San Francisco in 1997 to estimate the default probability of each bank, and uses the contagion risk caused by the change of default probability as the correlation coefficient to construct the Chinese bank network. Then we use the correspondence between the characteristics of complex network and systemic financial risk to determine the size of systemic risk from the perspective of network topology.

The remaining sections of this paper are as follows. In Section 2, we introduce all technical methods used in this paper, including the calculation of Correlation Coefficient and systemic risk, In Section 3, we present the network construction of Chinese banking system. Section 4 we present our measurement of systemic risk of Chinese banking system and results. In Section 5 we present our conclusions and final remarks.

\section{Method}

\subsection{Determination of Correlation Coefficient}

Bank default may lead to risk contagion among banks, and the extent of risk contagion is closely related to the degree of correlation. Therefore, this paper takes the CoRisk (CoRisk, Contagion Risk) caused by bank default (measured by the probability of default) as the correlation coefficient.

CoRisk consists of 2 parts: one is the additional risk of a bank due to the default of a related bank, which is recorded as $\mathrm{CoRisk}_{\text {in }}$; the other part is the CoRisk caused by a bank's default to its related banks, which is recorded as CoRisk out $_{\text {o }}$ Take bank i as an example:

$$
\begin{gathered}
\text { CoRisk }_{\text {in }}^{i}=1-\prod_{j \in N e(i)}\left(1-P D^{j}\right)^{\rho_{i j} \mid S} \\
\text { CoRisk }_{\text {out }}^{i}=1-\prod_{j \in N e(i)}\left(1-P D^{i}\right)^{\rho_{i j} \mid S}=1-\left(1-P D^{i}\right)^{\sum_{i \neq j} \rho_{i j} \mid S}
\end{gathered}
$$


Where Ne(i) represents the neighbor node of bank $\mathrm{i}$, $P D^{i}$ represents the probability of default of bank $\mathrm{i}, \mathrm{S}$ represents the system composed of banks, and $\rho_{i j} \mid S$ represents the partial correlation coefficient between bank $i$ and bank $j$ for a given banking system $\mathrm{S}$. During a certain period of time, the risk of bank i infecting bank $\mathrm{j}$ can be recorded as:

$$
\operatorname{CoRisk}_{i j}=1-\left(1-\mathrm{APD}^{i}\right)^{\rho_{i j}}
$$

APD $^{i}$ represents the average probability of default of bank $i$ over a period of time, $\rho_{i j}$ represents the partial correlation coefficient between bank I and bank J during the same period.

Whether there is a connecting edge between the 2 bank nodes depends on the comparison between the CoRisk value and the threshold value. If the CoRisk value is greater than the threshold value, there is a connecting edge between the 2 banks. If the CoRisk value is less than the threshold value, the connection between the 2 banks is not significant, and the connection between the two banks can be ignored. The direction of connection can be determined by comparing the CoRisk between banks. Take bank $i$ and bank $j$ as an example, if CoRisk $_{\mathrm{ij}}>$ CoRisk $_{\mathrm{ji}}$, the direction of the connected party is that bank i points to bank $\mathrm{j}$; if CoRisk $\mathrm{C}_{\mathrm{ij}}<$ CoRisk $_{\mathrm{ji}}$, then bank $\mathrm{j}$ points to bank $\mathrm{i}$. The adjacency matrix of the bank network is constructed as follows:

$$
\mathrm{X}=\left\{\begin{array}{r}
\text { if CoRisk } \mathrm{ij}_{\mathrm{ij}}<\mathrm{TV}, \text { then } \mathrm{X}_{\mathrm{ij}}=0 ; \text { if } \operatorname{CoRisk}_{\mathrm{ji}}<\mathrm{TV}, \text { then } \mathrm{X}_{\mathrm{ji}}=0 \\
\text { if } \operatorname{CoRisk}_{\mathrm{ij}}>\operatorname{CoRisk}_{\mathrm{ji}}>\mathrm{TV}, \text { then } \mathrm{X}_{\mathrm{ij}}=1, \mathrm{X}_{\mathrm{ji}}=0 \\
\text { if } \operatorname{CoRisk}_{\mathrm{ji}}>\operatorname{CoRisk}_{\mathrm{ij}}>\mathrm{TV}, \text { then } \mathrm{X}_{\mathrm{ij}}=0, \mathrm{X}_{\mathrm{ji}}=1
\end{array}\right.
$$

$\mathrm{X}$ represents the adjacency matrix, TV represents the threshold value of the correlation coefficient, $\mathrm{X}_{\mathrm{ij}}=1$ indicates that there is a connecting edge where node $i$ points to node $j$, $\mathrm{X}_{\mathrm{ij}}=0$ indicates that there is no connecting edge where node $\mathrm{i}$ points to node $\mathrm{j}$

\subsection{Measurement of Systemic Risk}

Systemic risk refers to the phenomenon that individual financial institutions spread the risk to multiple financial institutions due to default, thus leading to the vulnerability exposure of the entire financial system. Therefore, systemic risk depends on the risk status of individual financial institutions and the degree of interconnection with other institutions. According to the complex network theory, the degree centrality (DC) of the network can measure the influence of the node. The greater the degree centrality value, the higher the level of systemic risk in the banking system. The clustering coefficient (CO) can measure the degree of interconnection between neighboring nodes. The higher the $\mathrm{CO}$ value, the greater the systemic risk of the banking system. The eigenvector centrality (EC) can measure the impact of nodes on the whole network. Therefore, in the banking network, the systematic risk contribution of individual banks can be measured by the eigenvector centrality. The larger the EC value is, the higher the systemic risk level of the whole banking system is. Therefore, this paper uses the combination of the above 3 topographical indicators to measure the systematic risk of China's banking system, and takes into account the differences in the number of nodes of China's banking network in different periods, so the average of the above 3 indicators are used for comparison.

\subsubsection{Degree Centrality (DC)}

The degree centrality is a direct indicator of the importance of a node in a network, and the degree centrality is positively related to its importance in the network. Therefore, the greater the degree centrality value, the more important the bank at this node. In a directed network, degree centrality can be divided into out-degree centrality and in-degree centrality. Assuming that the network consists of $\mathrm{N}$ nodes, the out-degree centrality of node $\mathrm{i}$ is as follows:.

$$
D C_{i}^{\text {out }}=\frac{\sum_{j \in N, j \neq i} a_{i j}}{N-1}
$$

$D C_{i}^{\text {out }}$ is the out-degree centrality of node $\mathrm{i}, a_{i j}$ is used to measure whether there is a connected edge from node $i$ to node $\mathrm{j}$. if there is, then $a_{i j}=1$; if not, then $a_{i j}=0$ 。 Similarly, the in-degree centrality of node $i$ is as follows

$$
D C_{i}^{i n}=\frac{\sum_{j \in N, j \neq i} a_{j i}}{N-1}
$$

The degree centrality of node $\mathrm{i}$ is the sum of out-degree centrality and in-degree centrality.

$$
D C_{i}=D C_{i}^{\text {out }}+D C_{i}^{\text {in }}
$$

According to formula (7), the average degree centrality can be expressed as:

$$
\mathrm{ADC}=\frac{\sum_{i=1}^{N} D C_{i}}{N}
$$

Here, ADC represents the mean of degree centrality. The clustering coefficient can be used to describe the aggregation degree of interconnection among nodes.

\subsubsection{Clustering Coefficient (CO)}

Assuming node $\mathrm{i}$ in the network has $\mathrm{k}_{\mathrm{i}}$ neighbor nodes. The calculation formula of the clustering coefficient is as follows:

$$
C O_{i}=\frac{2 e_{i}}{k_{i}\left(k_{i}-1\right)}
$$

Here, $\mathrm{CO}_{i}$ represents the clustering coefficient of node i, $e_{i}$ is the actual number of connected edges of node $i$. The clustering coefficient of the whole network is represented by the mean value of the clustering coefficient of all nodes:

$$
\mathrm{ACO}=\frac{\sum_{i=1}^{N} \mathrm{CO}_{i}}{N}
$$

Here, ACO represents the mean value of the clustering 
coefficient.

\subsubsection{Eigenvector Centrality (EC)}

Assume that the eigenvector centrality of node $\mathrm{i}$ is $E C_{i}$, and the adjacency matrix of the network is $X$, the eigenvector centrality of node i can be expressed as:

$$
E C_{i}=\lambda \sum_{j} X_{i j} E C_{j}
$$

$\lambda$ is the proportional constant. Therefore, the mean of the eigenvector centrality (AEC) can be expressed as:

$$
\mathrm{AEC}=\frac{\sum_{i=1}^{N} E C_{i}}{N}
$$

Here, systemic risk (SR) is measured by the combination of the above 3 indicators, and its functional relationship is as follows:

$$
\mathrm{SR} \propto \exp (\mathrm{ADC}+\mathrm{ACo}+\mathrm{AEC})
$$

\section{Construction of China's Banking Network}

\subsection{Data Sources}

Considering the availability of data, we build the network based on the data of listed banks. According to the changes of the numbers of the listed banks, the research period is divided into four stages: T1 stage (2008-2010), with a total of 14 listed banks; At stage T2 (2011-2016), 2 more listed banks were added compared with stage T1, a total of 16 banks; In the T3 stage (2017-2018), 9 new listed banks were added compared with the T2 stage, with a total of 25 banks; and in the T4 stage (2019), 6 new listed banks will be added compared with the T3 stage, making a total of 31 banks. The data are mainly from the official websites of CSI. Here, short-term liabilities (SD) include the net increase of inter-bank borrowing, central bank loans, interbank funds, trading financial liabilities, derivative financial liabilities, sales and repurchase assets; Long-term liabilities (LD) include taxes payable, interest payable, agency business liabilities, bonds payable, deferred income tax liabilities, anticipated liabilities and other liabilities. As for deposits, $20 \%$ of the absorbed deposits are included in short-term liabilities and $80 \%$ in long-term liabilities. The market value of a bank's equity is determined by its total share capital and stock price. However, because some banks still have non-trable shares, therefore, E=NTS*SP + NNTS*NAPS (E represents equity value; NTS represents number of tradable shares; SP represents stock price; NNTS represents number of non tradable shares; NAPS represents net assets per share). The statistical characteristics of the sample data are shown in Table 1.

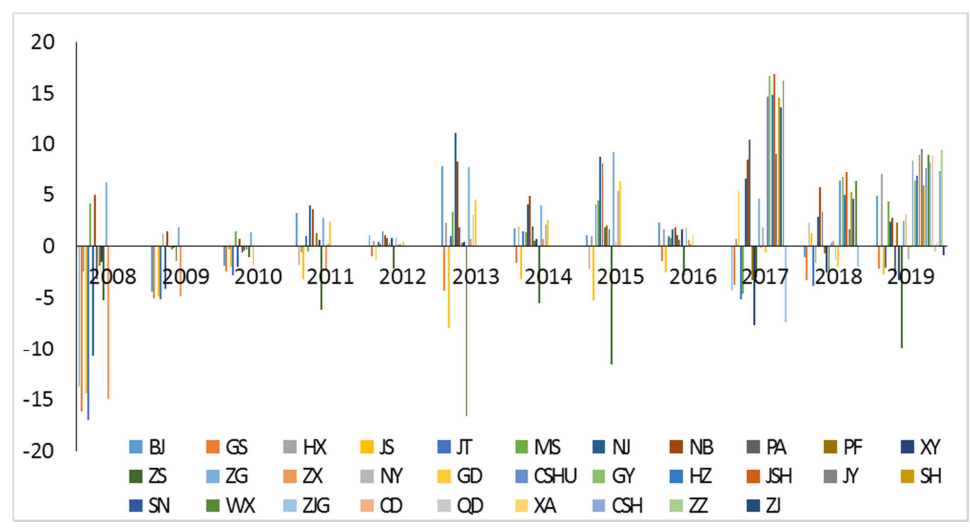

Figure 1. Changes of CoRisk in from 2008 to 2019.

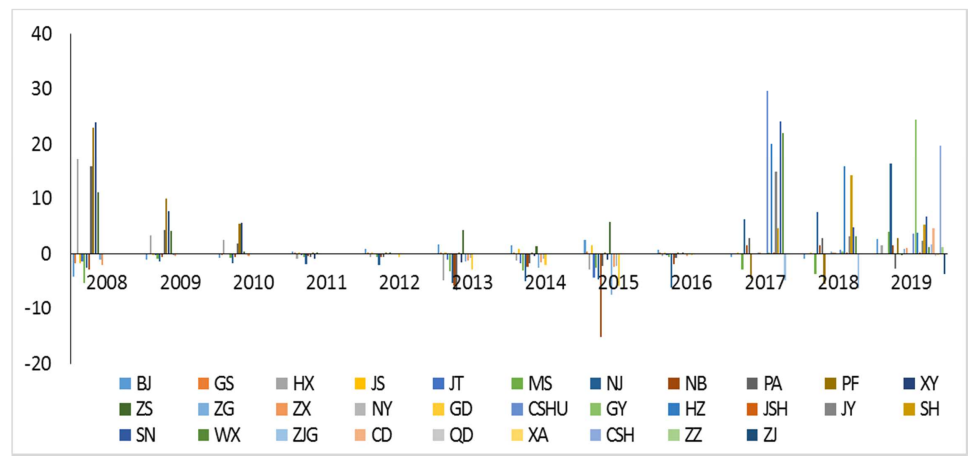

Figure 2. Changes of CoRisk outfrom 2008 to 2019.

Note: BJ is bank of Beijing, PA is Ping An bank, CSHU is Changshu bank, SN is Su Nong bank, GS is Industrial and Commercial Bank of China, PF is Shanghai Pudong development bank, CD is Chengdu bank, WX is bank of Wuxi, HX is Huaxia bank, XY is Xingye bank, GY is Guiyang bank, XA is bank of $\mathrm{Xi}$ 'an, JS is China construction bank, ZS is China Merchants bank, HZ is Hangzhou bank, CSH is Changsha bank, JT is bank of communications, ZG is the bank of China, JSU is Jiangsu bank, ZZ is Zhengzhou bank, MS is Minsheng bank, ZX is China CITIC bank, JN is Jiangyin bank, ZJ is Zhejiang bank, NJ is Nanjing bank, NY is agricultural bank, QD stands for Bank of Qingdao, ZJG stands for Bank of Zhangjiagang, NB stands for Bank of Ningbo, GD stands for China Everbright Bank and SH stands for Bank of Shanghai. 


\subsection{Correlation Coefficient of China's Banking Network}

Figures 1 and 2 show that the value of correlation coefficient of the bank network are larger in 2008, 2013-2015 and 2017-2019 which means there exist higher contagion risk. The main reasons are the severe impact of the international financial crisis in 2008, the pessimism caused by extreme events such as "money shortage" and "stock market crash" in China during 2013-2015, and the listing of a large number of small and medium-sized urban (rural) commercial banks during 2017-2019 which have a higher estimated default probability.

\subsection{China's Banking Network}

According to the correlation coefficient between banks, the network of China's banking system in the stages T1-T4 is plotted, as shown in Figure 3.

Table 1. The statistical characteristics of the sample data.

\begin{tabular}{llllllll}
\hline & Obs. & Mean & Min & Max & Std.dev & Median & Skewness \\
\hline SD & 219 & 16592.43 & 213.9923 & 73179.65 & 18155.36 & 8827.149 & 1.3711 \\
LD & 219 & 35213.47 & 551.3380 & 197147.6 & 44245.15 & 16044.73 & 1.6798 \\
E & 219 & 3582.539 & 90.0761 & 28162.28 & 4688.313 & 1620.610 & 2.1220 \\
\hline
\end{tabular}

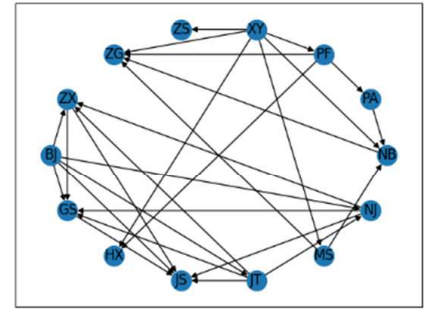

(a). Banking Network T1

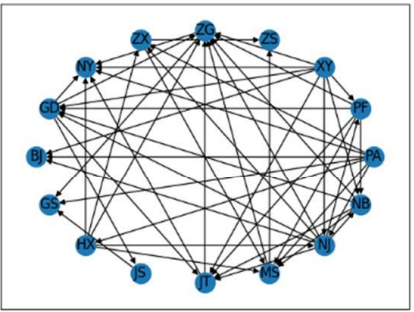

(b). Banking Network T2

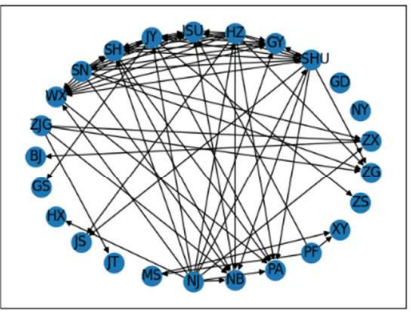

(c). Banking Network T3

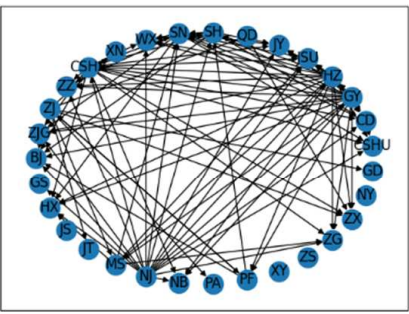

(d). Banking Network T4

Note: The meaning of the letters in Figure 3 are same as those in the note of Figure 2.

Figure 3. The Change of China's Banking Network.

Figure 3 shows the banking network of China is becoming more connected over time, and the risk contagion among banks is becoming more and more extensive. In stages $\mathrm{T} 1$ and $\mathrm{T} 2$, the risks were mainly transmitted from local banks and joint-equity commercial banks to state-owned banks, which played a positive role in the stability of the banking system; but in stages $\mathrm{T} 3$ and $\mathrm{T} 4$, the risks were mainly transmitted between local banks, and the role of local banks in the banking system was increasingly significant.

\section{Measurement of Systemic Risk}

We measure the systemic risk of China's banking industry in T1-T4 stage according to equation (13), as shown in Figure 4. The systemic risk of China's banking system shows a downward trend before 2018 (in stage T1 - T3). In stage T1, due to the severe impact of the international financial crisis, the systemic risk is at the highest level among sample period. The systemic risk of China's banking system in the T3 stage is reduced to the lowest level, but the systemic risk in the T4 stage shows a litter upward trend. The main reason is that the Sino- US trade frictions in 2018 had a negative impact on commercial banks. For example, the trade frictions indirectly affected commercial banks' credit, foreign exchange settlement, foreign exchange sales and other businesses through various trade barriers. The non-performing loan rate of commercial banks increased from $1.75 \%$ in the first quarter of 2018 to $1.86 \%$ in the fourth quarter of 2019 .

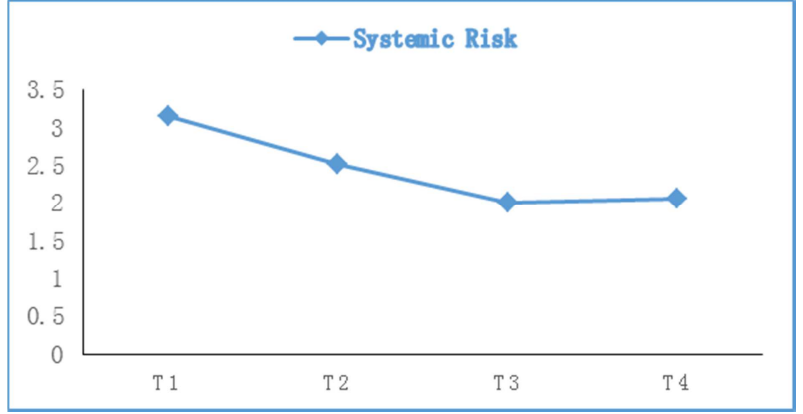

Figure 4. The changes of systemic risk of China's banking system.

In order to understand the reason better for the changes of systemic risk of China's banking system, let's further investigate the changes of the degree centrality, the clustering coefficient and the eigenvector centrality, which determine the systemic risk in each period, as shown in Figure 5.

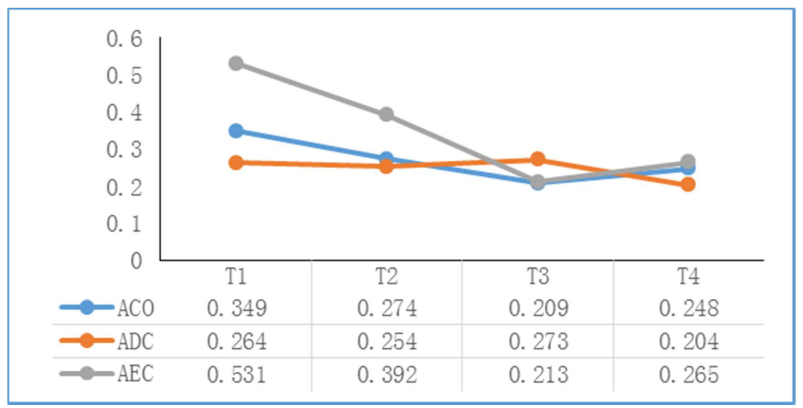

Figure 5. AEC, ACO and ADC in the T1-T4 stages. 
Figure 5 illustrate the change of degree centrality is very small in the T1-T3 stage, while the eigenvector centrality and clustering coefficient show a clearly significant downward trend. So we can say safely that the fall of systemic risk is consequent on the decline of eigenvector centrality and clustering coefficient in the T1-T3 stage. In T3-T4 stage, the eigenvector centrality and clustering coefficient both are on the rise, and the change of systemic risk is the same as that, which means that the eigenvector centrality and clustering coefficient are the main factors leading to the slow rise of systematic risk in T3-T4 stage, and the decrease of the degree centrality has an offsetting effect to some certain extent.

\section{Conclusion}

Based on the correlation coefficient calculated by the probability of default, this paper constructs the banking network of China, and use the combination of 3 topologic indicators (Eigenvector Centrality, Degree Centrality and Clustering Coefficient) to evaluate the systemic risk of the banking system in China. The basic conclusions of risk measurement are as follows:

The systemic risk of China's banking industry has shown a downward trend as a whole, located the lowest level in T3 period, and has a slightly upward trend after 2018 .

The Eigenvector Centrality and Clustering Coefficient are the main factors leading to the decrease of systematic risk in the banking system in China before 2018, and also they are the main reasons for the slight rise of systematic risk after 2018.

The network center is gradually transformed from state-owned banks to local banks. Before 2018, risk transmission was mainly taken place from local banks and joint-equity commercial banks to state-owned banks, which were the main risk bearers. After 2018, risk contagion mainly occurred among local banks, and some local banks role as systemically important ones.

Therefore, dissolving the systemic financial risk in China should strengthen the regulation of local banks. In particular, the high-risk leverage operations and excessively innovative business should be strictly supervised so as to prevent the expansion and spread of the negative effects stemmed from maturity mismatch, maturity transformation and credit transformation. At the same time, effective measures should be taken to improve the supervision efficiency of large state-owned banks who has high eigenvector centrality. The weak supervision of complex business areas with high technology content and high profits, such as derivatives, structured financing, merger and acquisition and back door listing, etc., may lead to the smooth risk contagion in the interbank network. It can greatly rise the eigenvector centrality and clustering coefficient, in turn, enhance the clustering of systemic risks.

\section{Acknowledgements}

This research has received financial support from the Fundamental Research Funds for the Central Universities, CUPL (20ZFG79001) and the Humanities and Social Science
Foundation of the Ministry of Education of China (Project No. 19YJA790046).

\section{References}

[1] Allen F., and D. Gale, Financial Contagion, Journal of Political Economy, 2000, 108 (1): 1-33.

[2] Marquez-Jaramillo S, Perez O P, Systemic Risk, Financial Contagion and Financial Fragility, Journal of Economic Dynamics \& Control, 2010, 34 (11): 2358-2374.

[3] Elliott M., Golub B., and M. O. Jackson, Financial Networks and Contagion, Social Science Electronic Publishing, 2012, 104 (10): 3115-53.

[4] Sui Cong. Tan Zhao-lin, and Wang Zhao-yao, A Network Perspective Measurement Method for Banking Systemic Risk, Chinese Journal of Management Science, 2016, 24 (5): 54-64.

[5] Larry, E., and T. Noe, Systemic Risk in Financial System, Management Science. 2011, 47 (2): 236-49.

[6] Stefano B., Michelangelo P., Rahul K., and Paolo T., DebtRank: Too Central to Fail? Networks, the FED and Systemic Risk. Scientific Report, 2012, Vol. 2, N. 8: 541.

[7] Ouyang Hong-bing. Liu Xiao-dong, An Analysis of the Systemic Importance and Systemic Risk Contagion Mechanism of China's Financial Institution on Network Analysis, Chinese Journal of Management Science, 2015, 23 (10): 30-37.

[8] Acharya, V., and A. Bisin, Counterparty Risk Externality: Centralized versus Over-the-counter Markets, Journal of Economic Theory, 2014, Vol. 149. 153-182.

[9] Liu Zhi-yang. The Risk Analysis of Chinese Inter-bank Debt Default Contagion Under Network Structure - A Two-dimensional Data Perspective of Inter-bank Debt and Financial Market, Modern Economic Science. 2020, 42 (03).

[10] Hautcsh, Nikolaus, Julia Schaumbrug, and Melanie Schienle, 2014a, Financial Network Systemic Risk Contribution, Review of Finance, forthcoming.

[11] Zhang Wei-ping, Zhuang Xin-tian, Li Yan-shuang. Stock Market Network Topology and Systematic Risk Contribution: Based on VaR Network Model, Engineering Management. 2020 (04).

[12] Li Yan-shuang, Zhuang Xin-tian. Zhang Wei-ping. Complex Network Structure and Centrality of China's Stock Market under the Extreme Fluctuation of Stock Index, Operations Research And Management Science. 2020 (07): 131-143.

[13] Giudici, P., Parisi, L., 2016. CoRisk: Measuring Systemic Risk through Default Probability Contagion. DEM Working Papers Series 116. University of Pavia, Department of Economics and Management. URL: https://EconPapers.repec.org/RePEc:pav:demwpp:demwp0116.

[14] Tafakori, L., Pourkhanali. A., and Rastelli R., 2019. Measuring Systemic Risk and Contagion in the European Financial Network. https://arxiv.org/pdf/1911.11488v1.pdf.

[15] Liu Y. and Yu, H.. Systemic Risk Indicator Measurement of Chinese Listed Banking System from the Perspective of Financial Network: Based on Improved Multi-factor Pricing Model, Future and Development, 2021, 45 (02). 